\title{
Hydrodynamic Cavitation-Assisted Synthesis of Nanocalcite
}

\author{
Shirish H. Sonawane, ${ }^{1}$ Sarang P. Gumfekar, ${ }^{1}$ Kunal H. Kate, ${ }^{1}$ Satish P. Meshram, ${ }^{1}$ \\ Kshitij J. Kunte, ${ }^{1}$ Laxminarayan Ramjee, ${ }^{1}$ Candrashekhar M. Mahajan, ${ }^{1}$ \\ Madan G. Parande, ${ }^{1}$ and Muthupandian Ashokkumar ${ }^{2}$ \\ ${ }^{1}$ Nanoscience and Engineering Research Group, Department of Chemical Engineering, Vishwakarma Institute of Technology, \\ 666-Upper Indira Nagar, Pune-411037, India \\ ${ }^{2}$ School of Chemistry, University of Melbourne, Melbourne VIC 3010, Australia
}

Correspondence should be addressed to Muthupandian Ashokkumar, masho@unimelb.edu.au

Received 11 November 2009; Revised 5 January 2010; Accepted 5 January 2010

Academic Editor: D. Murzin

Copyright (C) 2010 Shirish H. Sonawane et al. This is an open access article distributed under the Creative Commons Attribution License, which permits unrestricted use, distribution, and reproduction in any medium, provided the original work is properly cited.

\begin{abstract}
A systematic study was made on the synthesis of nanocalcite using a hydrodynamic cavitation reactor. The effects of various parameters such as diameter and geometry of orifice, $\mathrm{CO}_{2}$ flow rate, and $\mathrm{Ca}(\mathrm{OH})_{2}$ concentration were investigated. It was observed that the orifice diameter and its geometry had significant effect on the carbonation process. The reaction rate was significantly faster than that observed in a conventional carbonation process. The particle size was significantly affected by the reactor geometry. The results showed that an orifice with 5 holes of $1 \mathrm{~mm}$ size resulted in the particle size reduction to $37 \mathrm{~nm}$. The experimental investigation reveals that hydrodynamic cavitation may be more energy efficient.
\end{abstract}

\section{Introduction}

The effect of acoustic cavitation on different chemical reactions is well established. Gedanken [1] has reviewed the use of sonochemistry for fabrication of inorganic nanomaterials of various shapes, size, structure, and phases. Acoustic cavitation in liquids leads to two of major effects: physical (streaming, turbulence, microjet, shear, etc.) and chemical (radical production). While acoustic cavitationinduced chemical reactions have been successfully achieved, hydrodynamic cavitation is found to be efficient for applications involving continuous processing such as industrial carbonation operation. It is expected that hydrodynamic cavitation would increase the rate of carbonization reaction by lowering the mass transfer resistance. Hydrodynamic cavitation, in which a liquid is passed through constrictions, such as orifice plate or Venturi, has been found useful in specific chemical reactions. Hydrodynamic cavitation occurs due to the changes in the pressure of liquid flow in a pipe fitted with orifice or Venturi. A liquid experiences a sudden drop in pressure at downstream resulting in the collapse of formed cavities. The collapse of the cavities generates highly reactive radicals, which are responsible for specific chemical reactions. In gas-solid reactions, the dissolution of solids is enhanced due to the turbulent mixing generated by hydrodynamic cavitation. The vigorous mixing enhances the transport of gas solutes to the solid surface that results in an increase in the mass transfer and hence the overall reaction rate $[2-4]$.

Hydrodynamic cavitation has been found useful in the hydrolysis of fatty oils [5] and polymer solutions [6] and in the formation of styrene butadiene rubber nanosuspensions [7]. Morison and Hutchinson [8] have shown the limitations of the Weissler reaction as a model reaction for measuring efficiency of hydrodynamic cavitation. Senthil kumar et al. [9] and Moholkar et al. [10] have reported that the generation of cavities in a hydrodynamic reactor is very much dependent upon the design and the geometry of the reactors. Gogate and Pandit [11] have reviewed the effect of hydrodynamic cavitation on different industrially important reactions, such as the oxidation of toluene, xylene, and transesterification. Suslick et al. [12] studied dependence of tri iodide formation rate on the hydrodynamic pressure used to induce cavitation. Find and Moser [13] have reported on 


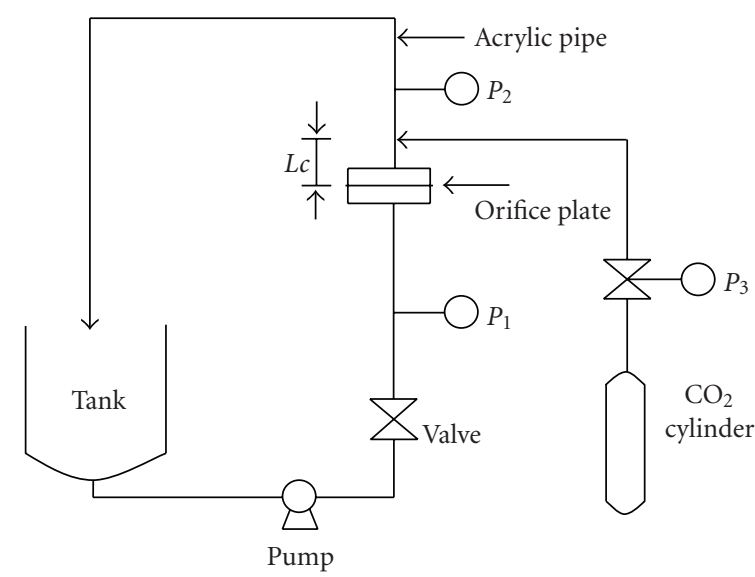

$L c$ cavitation length $P_{1}, P_{2}, P_{3}$ pressure gauges

(a)
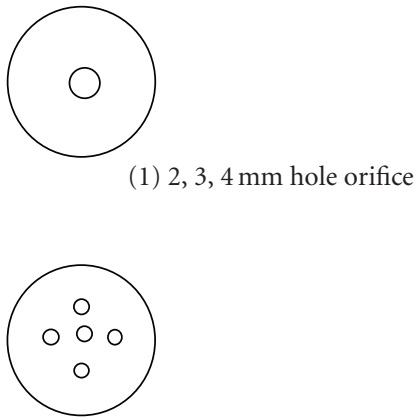

(2) $1 \mathrm{~mm} 5$ hole orifice

(b)

Figure 1: (a) Hydrodynamic cavitation setup for nano- $\mathrm{CaCO}_{3}$ production. (b) Orifice Configurations used for Cavitation.

the hydrodynamic cavitation-assisted synthesis of $\mathrm{Cu}-\mathrm{Zn}-\mathrm{Al}$ metal oxides using a mixture of aqueous $\mathrm{Na}_{2} \mathrm{CO}_{3}$ and $\mathrm{NaOH}$ solutions by precipitation.

Calcium carbonate synthesis is one typical example of the carbonation process, in which $\mathrm{CO}_{2}$ gas is bubbled through $\mathrm{Ca}(\mathrm{OH})_{2}$ slurry, which is also known as "reactive crystallization process." Lin et al. [14] studied the mass transfer effect for the reactive crystallization of calcite crystals in the presence of sodium tripolyphosphate in a multiphase system. The effect of ultrasound on the crystallization process has been extensively studied [15]. Sonawane et al. [16] synthesized nanosized $\mathrm{CaCO}_{3}$ particles using a sonochemical carbonation process in which $\mathrm{CO}_{2}$ gas was passed through a hole of an ultrasonic horn to achieve effective micromixing during the synthesis.

To the authors' knowledge, no systematic study has been carried out on the hydrodynamic cavitation-assisted synthesis of $\mathrm{CaCO}_{3}$. Hence, the aims of the current investigation were to synthesize $\mathrm{CaCO}_{3}$ nanoparticles using hydrodynamic cavitation under various experimental conditions and to study the effect of parameters such as reactor design on the crystal size and size distribution.

\section{Experimental}

2.1. Experimental Apparatus and Procedure. The experimental assembly (Figure 1(a)) consisted of a closed loop reactor with a holding tank of $5 \mathrm{~L}$ volume, a centrifugal pump (2880 RPM, $0.5 \mathrm{HP} / 0.37 \mathrm{KW}$ ) to recycle the $\mathrm{Ca}(\mathrm{OH})_{2}$ slurry, and two flanges for holding the orifice plate. Downstream pipe $(20 \mathrm{~mm}$ dia $)$ was made up of a transparent acrylic material in order to observe the generation of cavities. Upstream pipe was made of (SS 316) stainless steel. Pressure gauges were provided to measure the inlet pressure $\left(P_{1}\right)$ and fully recovered pressure $\left(P_{2}\right)$. Three different orifice plates and one having different geometry were used in the present study (Figure 1(b)). $\mathrm{CO}_{2}$ (99.9\% pure) gas was introduced at different flow rates from a hole drilled at the downstream part of pipe. Samples were withdrawn after every 3 minutes interval and were titrated against $\mathrm{HCl}$ and the $\mathrm{pH}$ and conductivity were measured. $\mathrm{Ca}(\mathrm{OH})_{2}$ of analytical grade was procured and used. HPLC grade water (Millipore) was used for preparing all the slurry suspension and filtered to get uniform particle size of $\mathrm{Ca}(\mathrm{OH})_{2}$. The recycling of slurry enabled the particles to be in suspension without settling at the bottom. The diameter of the orifice was calculated using $C_{v}$ values which was calculated from $P_{2}$ (downstream pressure), $\rho$ (density of water), $V_{0}$ (average velocity near orifice), and $P_{v}$ (vapor pressure of water) [17].

\subsection{Structural Properties and Particle Size Characterization.} Structural properties of the $\mathrm{CaCO}_{3}$ synthesized by the hydrodynamic cavitation process were evaluated using powder XRD (Philips PW 1800). The $\mathrm{Cu}-\mathrm{K} \alpha$ radiation (LFF tube $35 \mathrm{kV}, 50 \mathrm{~mA}$ ) was selected for the analysis. Transmission electron microscopy (TEM) was performed on Technai G20stwin working at $200 \mathrm{kV}$. The measurement of particle size distribution of the nanocrystals was done by dynamic light scattering technique (via Laser input energy of $632 \mathrm{~nm}$ ).

2.3. Cavitation Number $\left(C_{V}\right)$. In order to quantify various cavitation conditions and to represent appropriately the intensity of cavitation, the concept of cavitation number was utilized [6, 17].

The cavitation number is a dimensionless quantity defined as

$$
C_{v}=\frac{\left(P_{2}-P_{v}\right)}{\left(0.5 \times \rho \times V_{0}^{2}\right)},
$$

where $C_{v}$ is the cavitation number; $P_{2}$ is the downstream pressure; $P_{v}$ is the vapor pressure of water; $\rho$ is the density of water at $25^{\circ} \mathrm{C}, V_{0}$ is the average velocity near orifice.

For different orifice sizes $C_{v}$ values were calculated using (1) and presented in Table 1. Using appropriate orifice 
diameter and flow rate to reduce the pressure at vena contracta to fall below the threshold pressure for cavitation (which in many cases is the vapor pressure of water at that temperature) millions of cavities could be produced. The collapsing noise of cavities was heard using stethoscope in all the experiments when an orifice was used.

\section{Results and Discussions}

Prior to incorporating orifice into the experimental assembly, it was necessary to carry out a set of experiments to find out the consumption of $\mathrm{Ca}(\mathrm{OH})_{2}$ and the corresponding changes in the solution $\mathrm{pH}$ and conductivity (Figure 2). The above three variables were measured for $4 \% \mathrm{Ca}(\mathrm{OH})_{2}$ and $5 \mathrm{l} / \mathrm{min}$ flow rate of $\mathrm{CO}_{2}$. All three plots (Figures 2(a), 2(b), and $2(\mathrm{c})$ ) show three distinct regions corresponding to an induction period, nucleation, and precipitation. In the first region, nuclei are formed in the reaction mixture. In the second region nucleation around the crystals takes place, in the third region precipitation process occurs. In case of $\mathrm{Ca}(\mathrm{OH})_{2}$ consumption (Figure 2(a)), first constant period is observed as the solution is saturated with $\mathrm{Ca}(\mathrm{OH})_{2}$. The initial induction period (Figure 2(a)) where no change in $\left[\mathrm{Ca}^{2+}\right]$ was observed indicates that there was no spontaneous nucleation when the reaction was carried out without the orifice. The nucleation process appears to be slow and it takes relatively longer time (about 15 minutes) for the reaction to complete when the reaction was carried out in the pipe without orifice. It can also be noticed that the carbonation process was not $100 \%$ complete and there was some residual $\mathrm{Ca}(\mathrm{OH})_{2}$ present at the end of the reaction. It was also observed that the particles synthesized without the orifice are coarse in nature and they tend to agglomerate during drying.

It is observed that without the orifice there is a delay in the $\mathrm{pH}$ drop (Figure 2(b)) compared to the $\left[\mathrm{Ca}^{2+}\right]$ drop. This behavior is expected since the carbon dioxide was fed with a constant flow rate with a high initial concentration of $\mathrm{Ca}(\mathrm{OH})_{2}$ which led to no change in $\mathrm{pH}$. This data is also supported by the conductivity measurement (Figure 2(c)), which is an indirect measure of the total concentration of the charged species in the liquid phase. The first region of the conductivity plot gives information about the "induction time", in which the nuclei are formed by absorption of $\mathrm{CO}_{2}$ onto the surface of $\mathrm{Ca}(\mathrm{OH})_{2}$. The formation of $\mathrm{CaCO}_{3}$ leads to a decrease in the concentration of dissolved ionic species and hence the drop in the conductivity. The relatively slow precipitation process in the absence of the orifice increases the size $(101 \mathrm{~nm})$ of the crystals generated, as shown in Table 2 and discussed in the next section.

3.1. Effect of Orifice Diameter and Geometry of the Orifice on the Rate of Consumption of $\mathrm{Ca}(\mathrm{OH})_{2}$. Three different orifices with one hole of 2,3 , and $4 \mathrm{~mm}$ diameter and one orifice plate having 5 holes of $1 \mathrm{~mm}$ diameter were used for cavitation purposes as shown in Figure 1(b). Cavitation number $\left(C_{v}\right)$ and $\beta$ (ratio of orifice diameter to pipe diameter) for the above orifices are presented in Table 1. The consumption profiles of $\mathrm{Ca}(\mathrm{OH})_{2}$ slurry with different

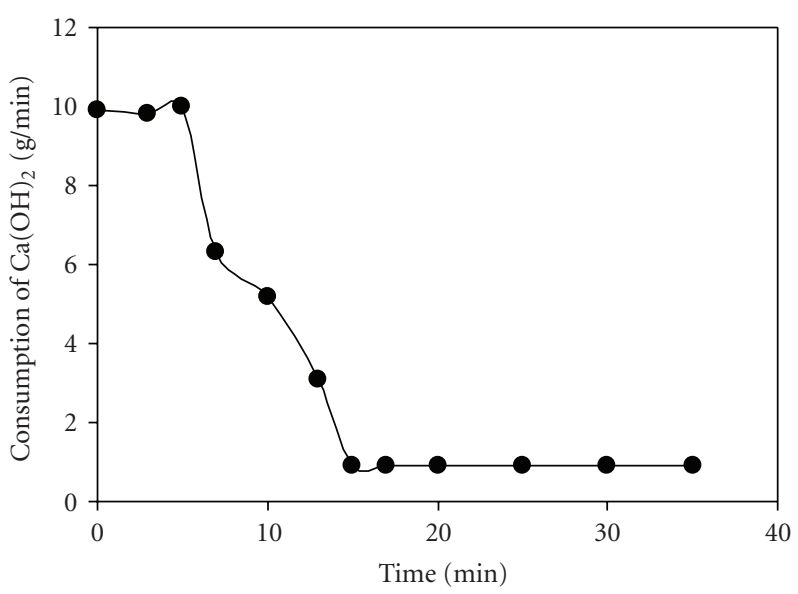

(a)

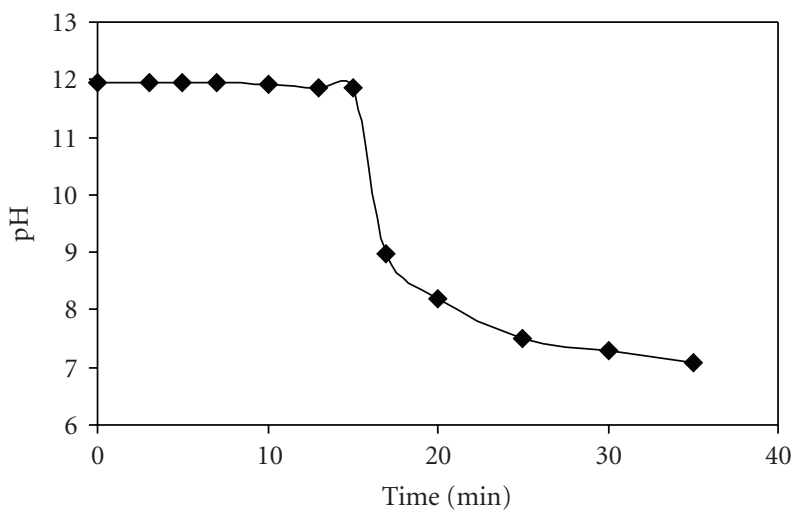

(b)

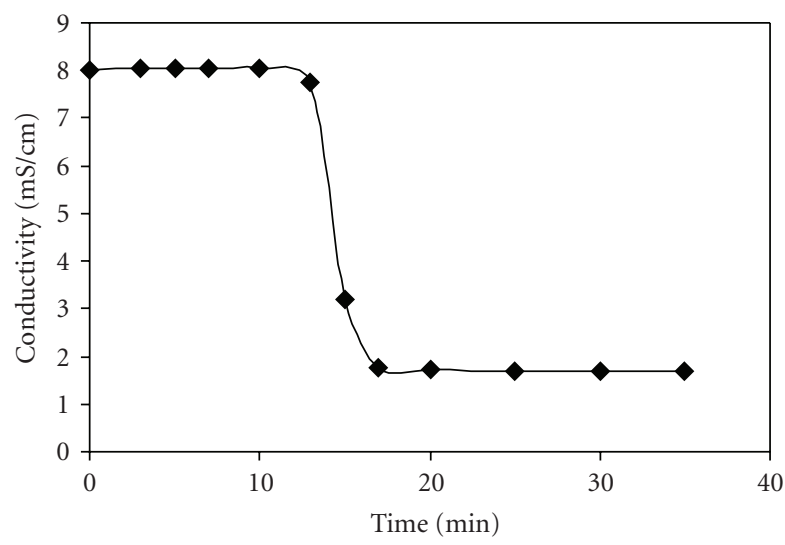

(c)

FIgure 2: (a) Consumption of $\mathrm{Ca}(\mathrm{OH})_{2}$ during the carbonation process without orifice $\left(4 \% \mathrm{Ca}(\mathrm{OH})_{2}\right.$ and $5 \mathrm{l} / \mathrm{min} \mathrm{CO}_{2}$ flow rate). (b) Change in $\mathrm{pH}$ during the carbonation process without orifice $\left(4 \% \mathrm{Ca}(\mathrm{OH})_{2}\right.$ and $5 \mathrm{l} / \mathrm{min} \mathrm{CO}_{2}$ flow rate). (c) Change in conductivity during the carbonation process without orifice $(4 \%$ $\mathrm{Ca}(\mathrm{OH})_{2}$ and $5 \mathrm{l} / \mathrm{min} \mathrm{CO}_{2}$ flow rate).

orifice diameters are shown in Figure 3. It can be seen that the rate of reaction is much faster with all orifices compared to the rate observed in the absence of an orifice (Figure 2). 
TABLE 1: Hydrodynamic conditions of different orifice plate used for experiments.

\begin{tabular}{lccc}
\hline Sr. No & Diameter of orifice & $\beta$ value (ratio of orifice diameter to pipe diameter) & $C_{v}$ (cavitation number) \\
\hline 1 & $2 \mathrm{~mm}$ & 0.10 & 0.15 \\
2 & $3 \mathrm{~mm}$ & 0.15 & 0.75 \\
3 & $4 \mathrm{~mm}$ & 0.20 & 2.15 \\
4 & 5 holes of $1 \mathrm{~mm}$ diameter & 0.05 & 0.21 \\
\hline
\end{tabular}

TABLE 2: Effect of slurry concentration and $\mathrm{CO}_{2}$ flow rates, orifice diameter on crystallite size (calculated from XRD), and particle size distribution (from TEM).

\begin{tabular}{|c|c|c|c|c|}
\hline $\mathrm{Ca}(\mathrm{OH})_{2}$ Slurry $\%$ & $\mathrm{CO}_{2} \mathrm{l} / \mathrm{min}$ & Orifice Dia. $\mathrm{mm}$ & Crystallite size $\mathrm{nm}$ & Particle size distribution $\mathrm{nm}$ \\
\hline \multicolumn{5}{|c|}{ Effect of change in $\mathrm{CO}_{2}$ flow rate } \\
\hline 4 & 3 & 4 & 74 & $65-92$ \\
\hline 4 & 5 & 4 & 54 & $62-53$ \\
\hline 4 & 7 & 4 & 47 & $35-55$ \\
\hline \multicolumn{5}{|c|}{ Effect of change in $\mathrm{Ca}(\mathrm{OH})_{2}$ concentration } \\
\hline 2 & 5 & 4 & 50 & $69-52$ \\
\hline 4 & 5 & 4 & 54 & $62-53$ \\
\hline 6 & 5 & 4 & 61 & $50-72$ \\
\hline \multicolumn{5}{|c|}{ Effect of change in orifice diameter } \\
\hline 4 & 5 & $1 \times 5$ holes & 37 & $29-38$ \\
\hline 4 & 5 & 2 & 39 & $30-41$ \\
\hline 4 & 5 & 3 & 49 & $43-56$ \\
\hline \multicolumn{5}{|c|}{ Without orifice } \\
\hline 4 & 5 & 4 & 54 & $62-53$ \\
\hline 4 & 5 & - & 101 & $90-168$ \\
\hline
\end{tabular}

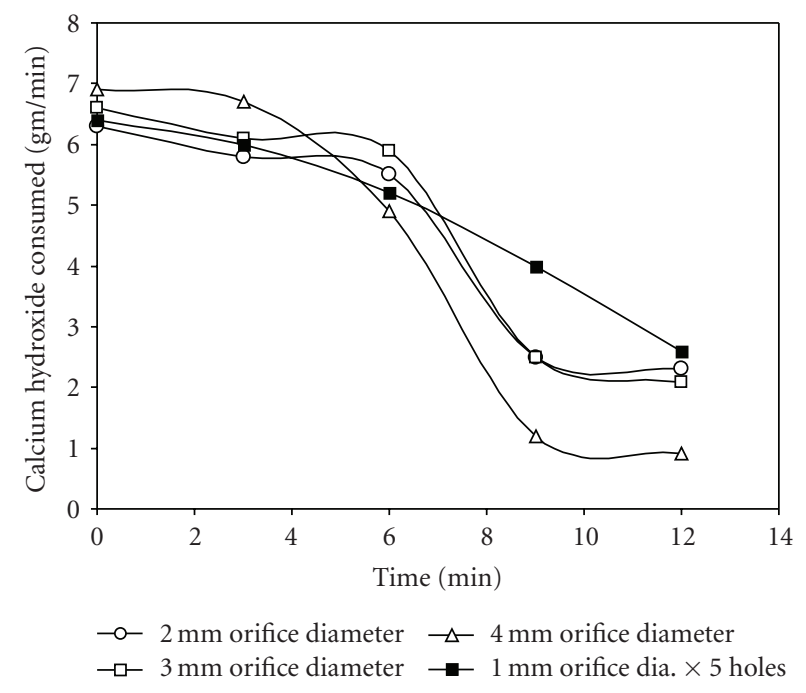

Figure 3: Effect of different orifice on consumption of $\mathrm{Ca}(\mathrm{OH})_{2}$ Slurry with respect of time (showing constant rate period and falling Rate periods) $\left(4 \% \mathrm{Ca}(\mathrm{OH})_{2}\right.$ and $5 \mathrm{l} / \mathrm{min}^{\mathrm{Co}_{2}}$ flow rate).

During the precipitation process, the rate of nucleation step is considered as the rate limiting step. It is observed that the nucleation is enhanced by the hydrodynamic cavitation and hence enhances the rate of precipitation as reported in earlier section. Nishida [18] has observed that acoustic cavitation generated physical effects of microstreaming that influenced the precipitation of calcium carbonate. Our investigation predicts the same effect on the calcium carbonate precipitation by hydrodynamic cavitation. Lyczko et al. [19] reported the effect of cavitation on the primary nucleation of potassium sulphate. They found that the induction period is drastically reduced in the presence of acoustic cavitation. Similar reduction in induction period and enhancement of primary nucleation (no external addition of seed particles) is observed in our case for calcium carbonate precipitation due to hydrodynamic cavitation. As in the case of without orifice, there is an induction period prior to the consumption of $\mathrm{Ca}(\mathrm{OH})_{2}$. However, the length of the induction period is shorter for the $4 \mathrm{~mm}$ dia orifice compared to the rest. This indicates that the $4 \mathrm{~mm}$ orifice initiates the reaction due to a relatively stronger shear forces generated by the hydrodynamic cavitation process. The larger diameter orifice might have generated the stronger hydrodynamic forces. On changing the geometry of orifice to $1 \mathrm{~mm}$ size, 5 holes (Figure 1(b)) orifice geometry, the reaction is initiated without any induction period. This arrangement also yielded smaller particle size during synthesis of calcium carbonate 


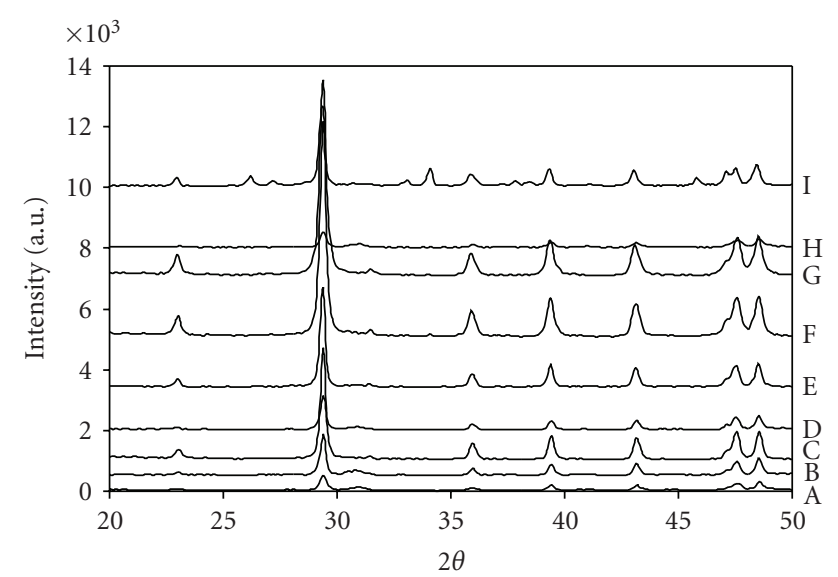

FIGURE 4: Effect of different experimental conditions on X-ray diffraction spectra. A: Without orifice, $4 \% \mathrm{Ca}(\mathrm{OH})_{2}$ slurry, $5 \mathrm{l} / \mathrm{min}$ $\mathrm{CO}_{2}$ flow rate; $\mathrm{B}: 1 \mathrm{~mm}$ orifice, $4 \% \mathrm{Ca}(\mathrm{OH})_{2}$, slurry $5 \mathrm{l} / \mathrm{min} \mathrm{CO}_{2}$ flow rate; $\mathrm{C}$ : $2 \mathrm{~mm}$ orifice $4 \% \mathrm{Ca}(\mathrm{OH})_{2}$, slurry $5 \mathrm{l} / \mathrm{min} \mathrm{CO}_{2}$ flow rate; D: $3 \mathrm{~mm}$ orifice $4 \% \mathrm{Ca}(\mathrm{OH})_{2}$ slurry $5 \mathrm{l} / \mathrm{min} \mathrm{CO}_{2}$ flow rate; E: $4 \mathrm{~mm}$ orifice $4 \% \mathrm{Ca}(\mathrm{OH})_{2}$, slurry $7 \mathrm{l} / \mathrm{min} \mathrm{CO}_{2}$ flow rate; $\mathrm{F}$ : $4 \mathrm{~mm}$ orifice $2 \% \mathrm{Ca}(\mathrm{OH})_{2}$, slurry $5 \mathrm{l} / \mathrm{min} \mathrm{CO}_{2}$ flow rate; $\mathrm{G}: 4 \mathrm{~mm}$ orifice $6 \% \mathrm{Ca}(\mathrm{OH})_{2}$ slurry, $5 \mathrm{l} / \mathrm{min} \mathrm{CO}_{2}$ flow rate; $\mathrm{H}: 4 \mathrm{~mm}$ orifice $4 \% \mathrm{Ca}(\mathrm{OH})_{2}$ slurry, $3 \mathrm{CO}_{2} \mathrm{l} / \mathrm{min}$ flow rate; $\mathrm{I}: 4 \mathrm{~mm}$ orifice, $4 \%$ $\mathrm{Ca}(\mathrm{OH})_{2}$ slurry, $5 \mathrm{CO}_{2} \mathrm{l} / \mathrm{min}$ flow rate.

in the carbonation process. X-ray diffraction analysis was carried out for all the powder samples as shown in Figure 4. The grain size (crystallite size) was calculated for all the samples by using Debye Scherrer formula:

$$
X_{d}=\frac{k \lambda}{\beta \cos \theta},
$$

where $k=0.9, \beta=$ FWHM, and $\theta$ is glancing angle of X-rays with the sample holder, $\lambda=1.5405 \AA$.

As shown in Table 2 , the $1 \mathrm{~mm} \times 5$ holes orifice generated the smallest crystal size of $37 \mathrm{~nm}$. The powder XRD is found to be preferably oriented along ( $\left(\begin{array}{llll}1 & 0 & 1 & 0\end{array}\right)$ plane for samples including the $\mathrm{CaCO}_{3}$ without the orifice. No effect is observed on phases due to change in orifice diameter and geometry of orifice. Single calcite phase is observed in all the samples. Wide particle size distribution was observed for the sample without orifice ranging from 90 to $168 \mathrm{~nm}$ as shown in Figure 5(a), while narrow particle size distribution is observed ranging from 30 to $41 \mathrm{~nm}$ for the orifice with $2 \mathrm{~nm}$ orifice as shown in Figure 5(b). The confirmation of calcite phase observed in the XRD data is confirmed by the TEM images. As shown in Figure 6, the TEM image shows the cubic shape particles of calcite particles synthesized using $4 \mathrm{~mm}$ orifice diameter $4 \%$ slurry concentration and $51 / \mathrm{min}$ $\mathrm{CO}_{2}$ flow rate.

The data shown in Figures 4-6 and Table 2 indicates that the rate of consumption of calcium hydroxide slurry during $\mathrm{CaCO}_{3}$ synthesis using hydrodynamic cavitation is significantly dependent on the geometry of the orifice and its cavitation number. The use of orifice geometry significantly reduces the grain size and hence, increasing the surface area of the synthesized calcite and making it more suitable for the surface coatings applications. Patil and
Pandit [7] also have reported the reduction in particle size of styrene butadiene rubber nanoparticles by using the different geometries of orifice used in hydrodynamic cavitation. Luque de Castro and Priego-Capote [20] reported the influence of ultrasonic power and horn tip onto the carbonation process. They found that acoustic cavitation had an effect on the consumption of calcium hydroxide, which shows similar reduction in the induction period and particle size reported in Figure 3 and Table 2, respectively.

Figure 7 shows the effect of cavitation number $\left(C_{v}\right)$ and the ratio of orifice diameter to pipe diameter ( $\beta$ factor) on the rate of consumption of $\mathrm{Ca}(\mathrm{OH})_{2}$ slurry. It is found that the rate of consumption of $\mathrm{Ca}(\mathrm{OH})_{2}$ increases with an increase in the ratio of orifice diameter to plate diameter $(\beta) . \mathrm{Ca}(\mathrm{OH})_{2}$ consumption rate has gone up exponentially with an increase of $\beta$ factor which indicates that there is a significant effect of geometry of orifice plate. We speculate that the $\beta$ factor has significant influence on the generation of hydrodynamic cavitation. Generally for effective cavitation, it is recommended that the cavitation number should be less than 2.5 and it is important to know that severity of cavitation increases with decreasing the cavitation number [10], which is the case for all orifices. The higher cavitation number for $4 \mathrm{~mm}$ orifice also supports the higher rate observed in Figure 3.

\subsection{Effect of $\mathrm{CO}_{2}$ Flow Rates onto the Conductivity for Orifice} with $4 \mathrm{~mm}$ Diameter. A change in the electrical conductivity of the solution with respect to time in the presence of $4 \mathrm{~mm}$ diameter orifice is presented in Figure 8. Three different flow rates $(3,5$, and $71 / \mathrm{min})$ were used at constant $4 \% \mathrm{Ca}(\mathrm{OH})_{2}$ concentration. It is found at higher flow rate $(7 \mathrm{l} / \mathrm{min})$ that the drop in the solution conductivity is faster in comparison to the other two flow rates. It can also be observed that there is small induction time for higher flow rate $71 / \mathrm{min}$ while longer induction time for 3 and $51 / \mathrm{min}$ flow rates. Induction time for $71 / \mathrm{min}$ flow rate is less than 5 minute, while for 3 and $51 / \mathrm{min}$ induction time is nearly 10 minute. In comparison to other two flow rates, numbers of nuclei are formed at $7 \mathrm{l} / \mathrm{min}$ and hence the drop in conductivity is faster. With increasing the $\mathrm{CO}_{2}$ flow rate, the reduction in crystallite size and no change in calcite phase are observed as shown in Figure 4 and Table 2. At 3, 5, 7 1/min flow rates, the crystallite size was found 74,54 , and $47 \mathrm{~nm}$, respectively. The particle size distribution is found to be narrow at higher flow rate $(7 \mathrm{l} / \mathrm{min})$ ranging from 35 to $55 \mathrm{~nm}$.

\subsection{Effect of $\mathrm{Ca}(\mathrm{OH})_{2}$ Slurry Concentration on the Rate of} Reaction. Effect of three different $\mathrm{Ca}(\mathrm{OH})_{2}$ slurry concentrations on the solution conductivity at $4 \mathrm{~mm}$ orifice diameter is shown in Figure 9. At higher $\mathrm{Ca}(\mathrm{OH})_{2}$ concentration $(6 \%)$, the drop in the conductivity takes longer time in comparison to $2 \% \mathrm{Ca}(\mathrm{OH})_{2}$ slurry concentration which indicates that there is longer induction time for higher $\mathrm{Ca}(\mathrm{OH})_{2}$ and shorter induction time for low $\mathrm{Ca}(\mathrm{OH})_{2}$ slurry concentration. At $2 \%$ of slurry concentration the drop in conductivity occurs very fast (within 5 minutes). It is also found that the available $\mathrm{CO}_{2}$ gas concentration is more 


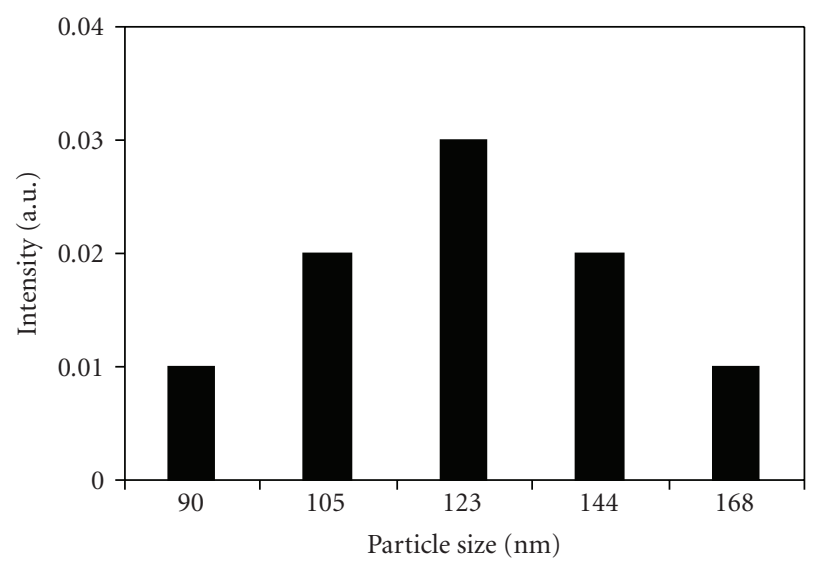

(a)

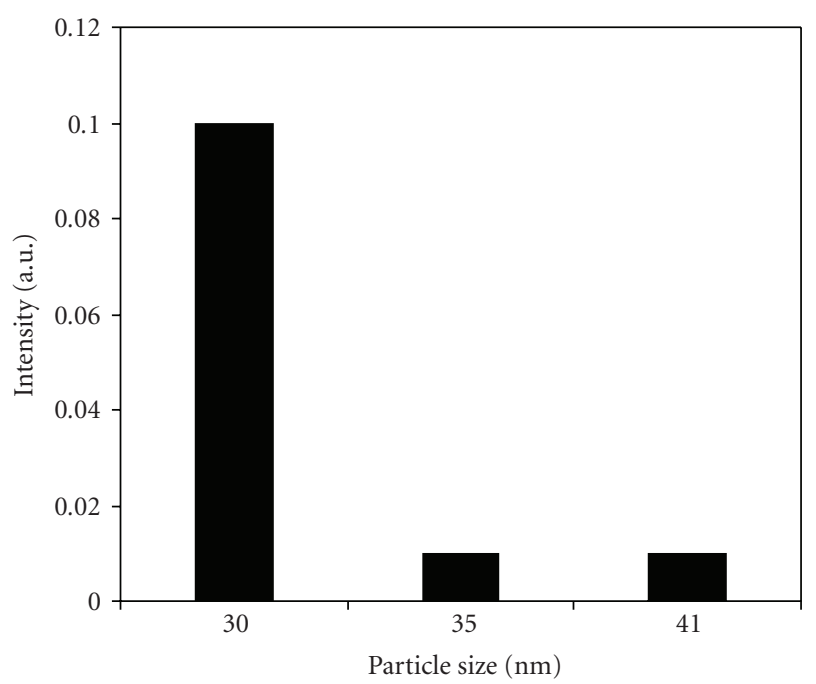

(b)

Figure 5: (a) Particle size distribution of $\mathrm{CaCO}_{3}$ particles synthesized without orifice in the pipe $\left(4 \% \mathrm{Ca}(\mathrm{OH})_{2}\right.$ slurry, $5 \mathrm{l} / \mathrm{min} \mathrm{CO}_{2}$ flow rate). (b) Particle size distribution of $\mathrm{CaCO}_{3}$ particles synthesized using Hydrodynamic cavitation $\left(2 \mathrm{~mm}\right.$ orifice, $4 \% \mathrm{Ca}(\mathrm{OH})_{2}$ slurry, $51 / \mathrm{min} \mathrm{CO}_{2}$ flow rate).

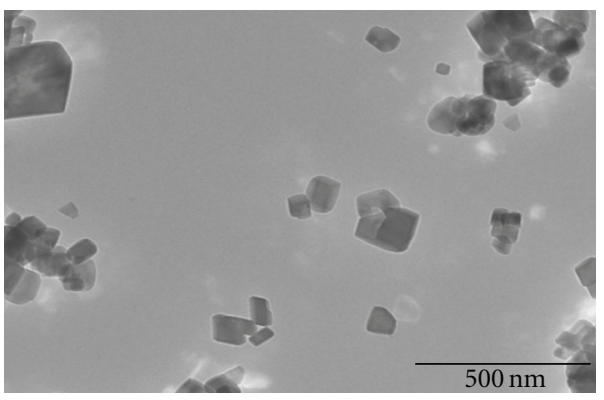

Figure 6: TEM Image of nano- $\mathrm{CaCO}_{3}$ synthesized using hydrodynamic cavitation $\left(4 \mathrm{~mm}\right.$ orifice, $4 \% \mathrm{Ca}(\mathrm{OH})_{2}$ slurry, $5 \mathrm{l} / \mathrm{min}, \mathrm{CO}_{2}$ flow rate) (Scale $500 \mathrm{~nm}$ ).

for the $2 \%$ slurry and hence induces the massive nuclei formation.

The effect of calcium hydroxide slurry concentration on the $\mathrm{pH}$ values, that is, the completion of reaction was also studied. The reaction was carried out at constant flow rate of $\mathrm{CO}_{2}\left(5 \mathrm{l} / \mathrm{min} \mathrm{CO}_{2}\right.$ flow rate) and by using $4 \mathrm{~mm}$ diameter of orifice. It is seen that the completion of reaction takes longer time (20 minutes) with 6\% slurry concentration and on the other hand $2 \%$ slurry takes less that 10 minutes for completion. The constant period zone and falling rate zone are observed in the case of 4 and $6 \%$ slurry, while 2\% slurry shows only falling rate period. As shown in Table 2, with increasing the concentration of calcium hydroxide there is an increase in the crystallite size. This observation suggests that increasing the $\mathrm{Ca}(\mathrm{OH})_{2}$ has no favorable effect on the crystallite size. The XRD patterns for calcite synthesized at different $\mathrm{Ca}(\mathrm{OH})_{2}$ concentration indicate that the calcite powder is crystalline in nature and exhibits pure calcite phase [21].

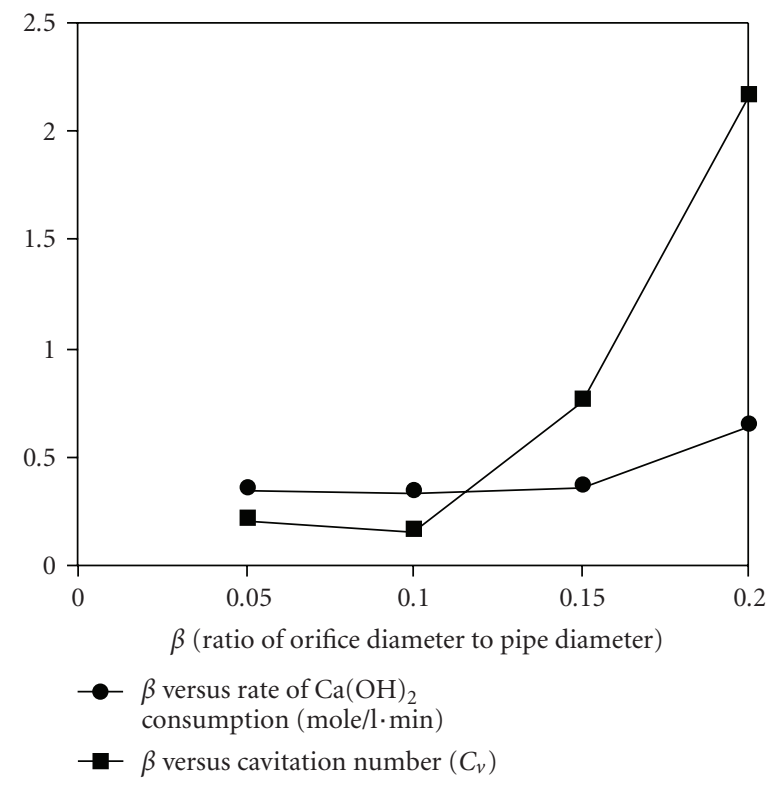

FIgURE 7: Effect of $\beta$ factor onto rate of calcium hydroxide consumption and cavitation number $\left(C_{v}\right)$.

\section{Conclusion}

This study has demonstrated that nanocalcite can be synthesized by using a hydrodynamic cavitation reactor, without formation of vaterite phase. The effects of three different orifice diameters and the geometry of orifice were evaluated. The average grain size of the calcite synthesized without cavitation was found to be $101 \mathrm{~nm}$. It is seen that there is a wide distribution of particle size in the range $90-168 \mathrm{~nm}$ for the setup without an orifice. The change in the geometry of orifice has resulted significant effect on the crystallite size. In 


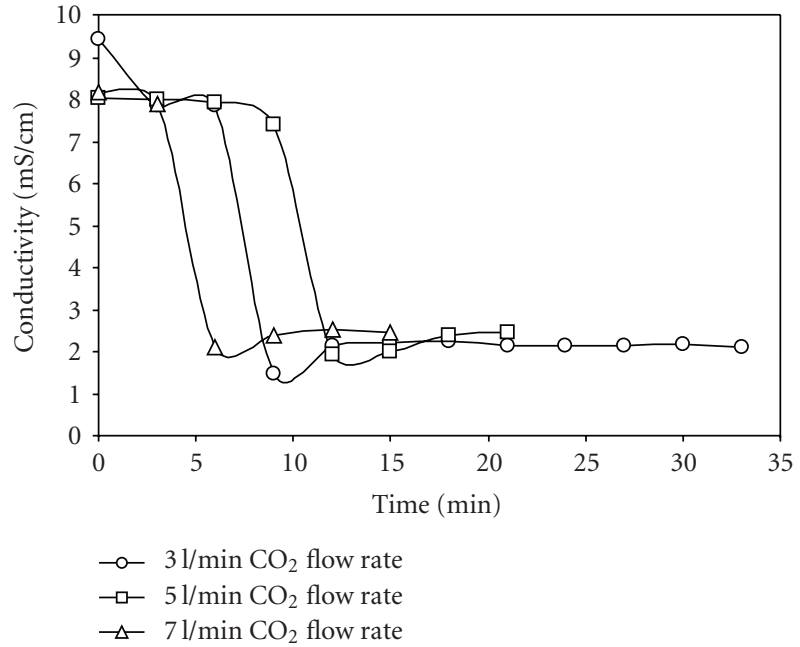

FIGURE 8: Effect of $\mathrm{CO}_{2}$ flow rates on conductivity of reaction mixture (orifice diameter $4 \mathrm{~mm}, 4 \% \mathrm{Ca}(\mathrm{OH})_{2}$ slurry concentration).

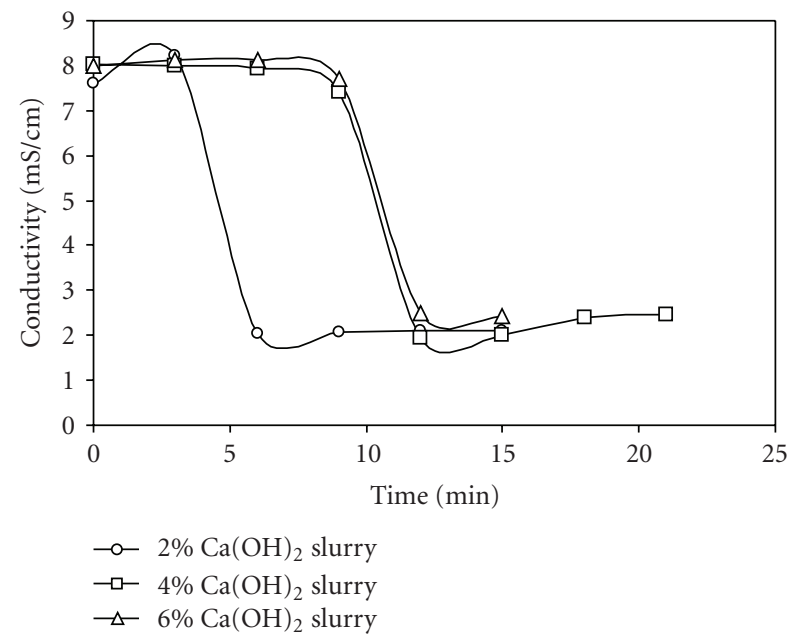

Figure 9: Effect of $\mathrm{Ca}(\mathrm{OH})_{2}$ slurry concentration onto the conductivity at $5 \mathrm{l} / \mathrm{min} \mathrm{CO}_{2}$ gas flow rate.

case of 5 holes of $1 \mathrm{~mm}$ size orifice found to give reduced size of size of $37 \mathrm{~nm}$.

\section{Acknowledgments}

S. H. Sonawane acknowledges the Department of Science and Technology (Govt of India) for providing the funding for fast track project under the Grant no. SR/FTP/ETA-35/2007 and BOYSCAST fellowship through Grant no. SR/BY/E07/2008. The authors are also thankful to Professor A. B. Pandit (UICT, Mumbai) for his valuable suggestion to carry experimental work.

\section{References}

[1] A. Gedanken, "Using sonochemistry for the fabrication of nanomaterials," Ultrasonics Sonochemistry, vol. 11, no. 2, pp. 47-55, 2004.
[2] P. R. Gogate, "Cavitational reactors for process intensification of chemical processing applications: a critical review," Chemical Engineering and Processing, vol. 47, no. 4, pp. 515-527, 2008.

[3] P. R. Gogate and A. B. Pandit, "Hydrodynamic cavitation reactors: a state of the art review," Reviews in Chemical Engineering, vol. 17, no. 1, pp. 1-85, 2001.

[4] S. Kakaraniya, A. Gupta, and A. Mehra, "Reactive precipitation in gas-slurry systems: the $\mathrm{CO}_{2}-\mathrm{Ca}(\mathrm{OH})_{2}-\mathrm{CaCO}_{3}$ system," Industrial and Engineering Chemistry Research, vol. 46, no. 10, pp. 3170-3179, 2007.

[5] A. B. Pandit and J. B. Joshi, "hydrolysis of fatty oils: effect of cavitation," Chemical Engineering Science, vol. 48, no. 19, pp. 3440-3442, 1993.

[6] M. M. Chivate and A. B. Pandit, "Effect of sonic and Hydrodynamic cavitation on aqueous polymeric solutions," Indian Chemical Engineering, vol. 35, pp. 52-57, 1993.

[7] M. N. Patil and A. B. Pandit, "Cavitation-a novel technique for making stable nano-suspensions," Ultrasonics Sonochemistry, vol. 14, no. 5, pp. 519-530, 2007.

[8] K. R. Morison and C. A. Hutchinson, "Limiting of the Weissler reaction as model reaction for measuring the efficiency of hydrodynamic cavitation," Ultrasonic Sonochemistry, vol. 16, pp. 176-183, 2009.

[9] P. Senthil Kumar, M. Sivakumar, and A. B. Pandit, "Experimental quantification of chemical effects of hydrodynamic cavitation," Chemical Engineering Science, vol. 55, no. 9, pp. 1633-1639, 2000.

[10] V. S. Moholkar, P. Senthilkumar, and A. B. Pandit, "Hydrodynamic cavitation for sono-chemical effect," Ultrasonics Sonochemistry, vol. 6, pp. 53-65, 1999.

[11] P. R. Gogate and A. B. Pandit, "A review and assessment of hydrodynamic cavitation as a technology for the future," Ultrasonics Sonochemistry, vol. 12, no. 1-2, pp. 21-27, 2005.

[12] K. S. Suslick, M. M. Mdleleni, and J. T. Ries, "Chemistry induced by hydrodynamic cavitation," Journal of the American Chemical Society, vol. 119, no. 39, pp. 9303-9304, 1997.

[13] J. W. Find and R. Moser, "Preparation and structural properties of $\mathrm{Cu}-\mathrm{Zn}$-Al-oxides: a comparative study between the hydrodynamic-cavitation and classical route," Journal of Materials Science, vol. 38, pp. 1917-1924, 2003.

[14] R. Lin, J. Zhang, and Y. Bai, "Mass transfer of reactive crystallization in synthesizing calcite nanocrystal," Chemical Engineering Science, vol. 61, no. 21, pp. 7019-7028, 2006.

[15] M. He, E. Forssberg, Y. Wang, and Y. Han, "Ultrasonicationassisted synthesis of calcium carbonate nanoparticles," Chemical Engineering Communications, vol. 192, no. 10-12, pp. 1468-1481, 2005.

[16] S. H. Sonawane, S. R. Shirsath, P. K. Khanna, et al., "An innovative method for effective micro-mixing of $\mathrm{CO}_{2}$ gas during synthesis of nano-calcite crystal using sonochemical carbonization," Chemical Engineering Journal, vol. 143, no. 13, pp. 308-313, 2008.

[17] C. Mishra and Y. Peles, "An experimental investigation of hydrodynamic cavitation in micro-Venturis," Physics of Fluids, vol. 18, no. 10, pp. 103-109, 2006.

[18] I. Nishida, "Precipitation of calcium carbonate by ultrasonic irradiation," Ultrasonics Sonochemistry, vol. 11, no. 6, pp. 423428, 2004.

[19] N. Lyczko, F. Espitalier, O. Louisnard, and J. Schwartzentruber, "Effect of ultrasound on the induction time and the metastable zone widths of potassium sulphate," Chemical Engineering Journal, vol. 86, no. 3, pp. 233-241, 2002. 
[20] M. D. Luque de Castro and F. Priego-Capote, "Ultrasoundassisted crystallization (sonocrystallization)," Ultrasonics Sonochemistry, vol. 14, no. 6, pp. 717-724, 2007.

[21] G. Montes-Hernandez, F. Renard, N. Geoffroy, L. Charlet, and J. Pironon, "Calcite precipitation from $\mathrm{CO}_{2}-\mathrm{H}_{2} \mathrm{O}-\mathrm{Ca}(\mathrm{OH})_{2}$ slurry under high pressure of $\mathrm{CO}_{2}$," Journal of Crystal Growth, vol. 308, pp. 228-236, 2007. 

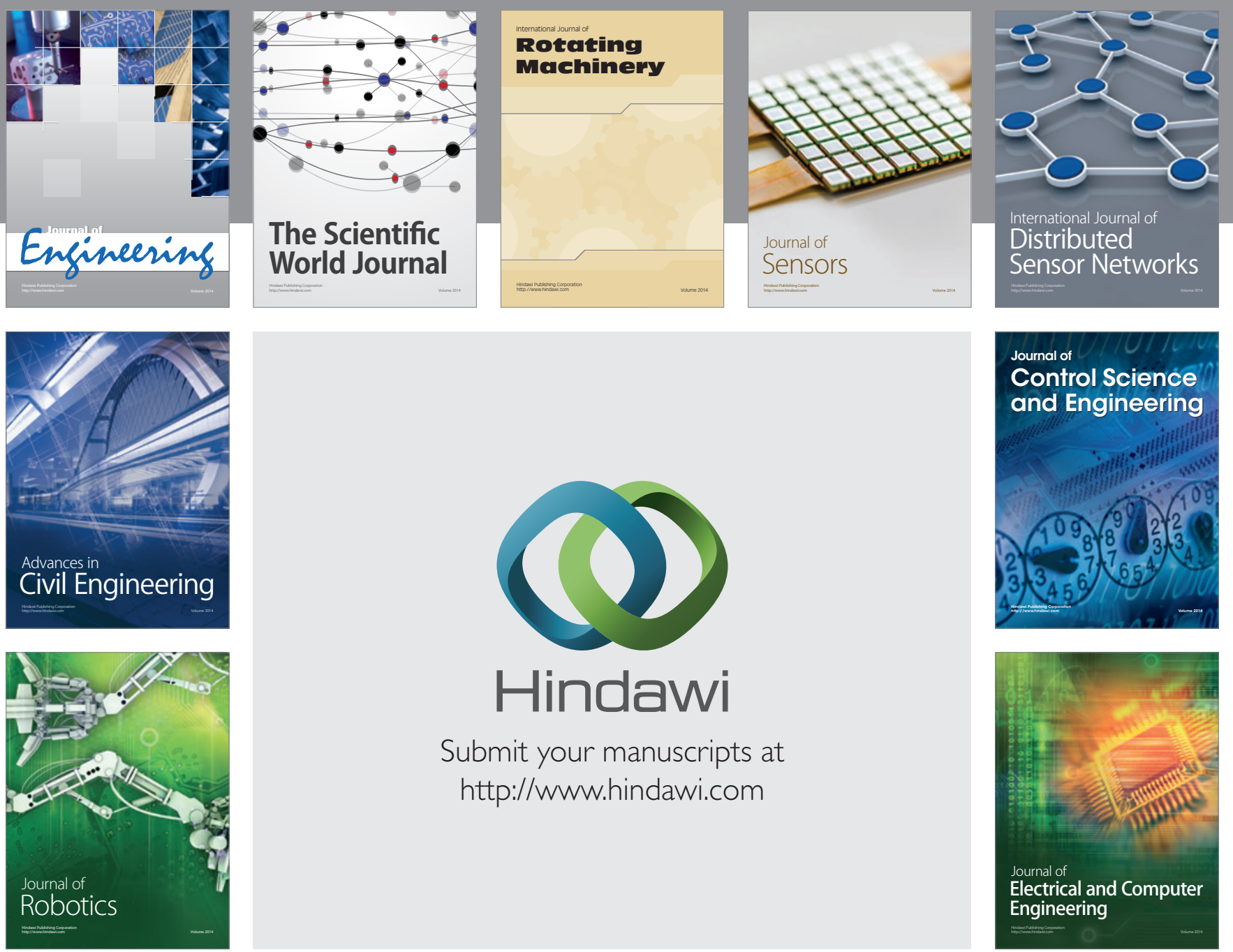

Submit your manuscripts at

http://www.hindawi.com
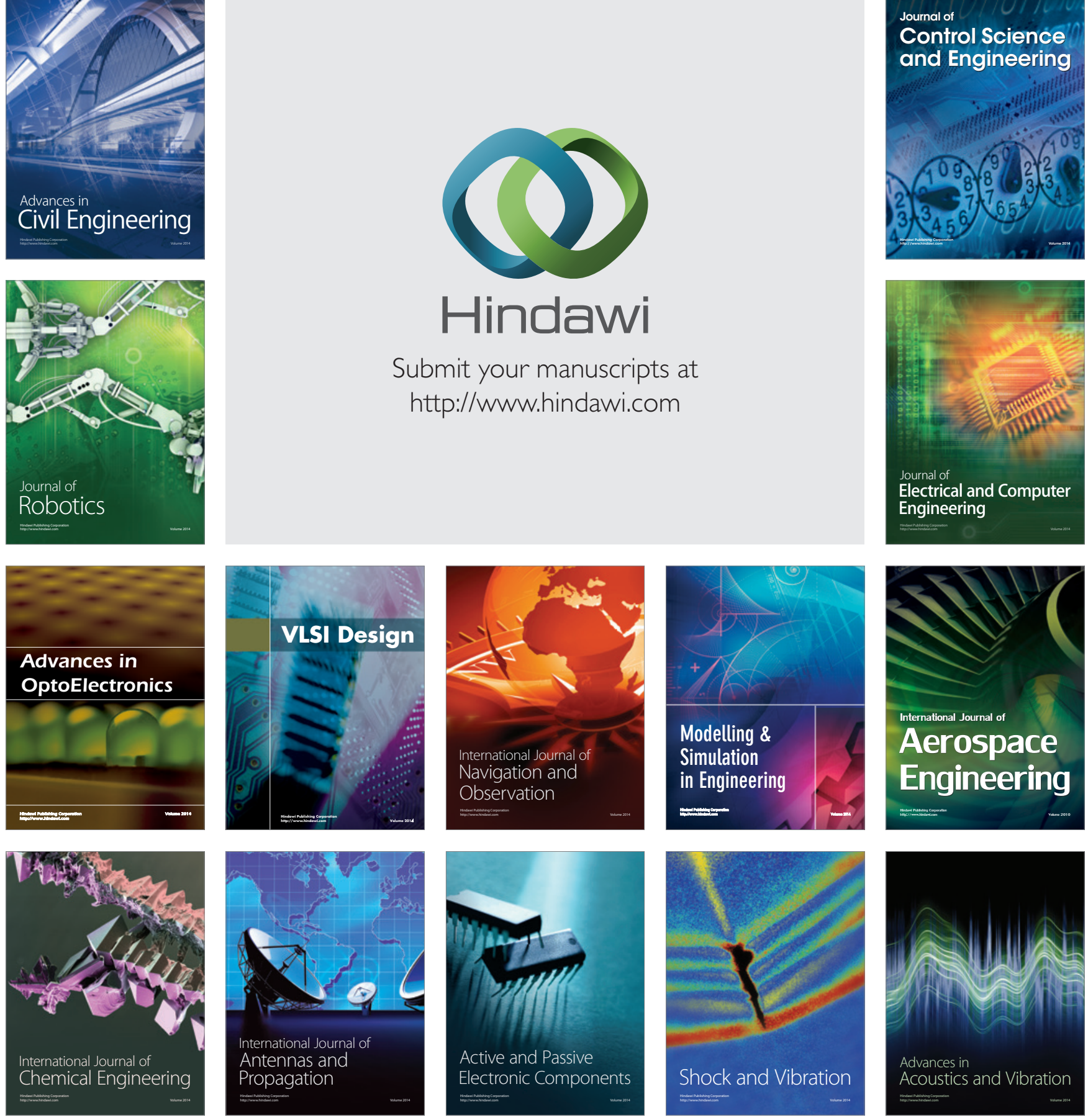